\title{
Guanidinium Thiocyanate Selective Ostwald Ripening Induced Large Grain For High Performance Perovskite Solar Cells
}

Ngoc Duy Pham, ${ }^{1}$ Vincent Tiing Tiong, ${ }^{1}$ Disheng Yao, ${ }^{1}$ Wayde Matens, ${ }^{1}$ Antonio Guerrero, ${ }^{2}$ Juan Bisquert $^{2}$ and Hongxia Wang ${ }^{1 *}$

${ }^{1}$ School of Chemistry, Physics and Mechanical Engineering, Science and Engineering Faculty, Queensland University of Technology, Brisbane, Australia

${ }^{2}$ Institute of Advanced Materials (INAM), Universitat Jaume I, 12006 Castelló, Spain

Corresponding author:

*E-mail: hx.wang@qut.edu.au 


\section{ABSTRACT}

Organic-inorganic lead halide perovskite has become one of the most attractive materials for future low-cost high-efficiency solar technology. However, the polycrystalline nature of perovskite thin-film often possesses an exceptional density of defects, especially at grain boundaries (GBs) and film surface, limiting further improvement in the power conversion efficiency (PCE) of the perovskite device. Here, we report a simple method to reduce GBs and to passivate the surface of a methylammonium lead triiodide $\left(\mathrm{MAPbI}_{3}\right)$ film by guanidinium thiocyanate (GUTS)-assisted Ostwald ripening post treatment. High-optoelectronic quality $\mathrm{MAPbI}_{3}$ film consisting of micron-sized grains were synthesized by posttreating a $\mathrm{MAPbI}_{3}$ film with GUTS/isopropanol solution (4 mg/mL, GUTS-4). Analysis of the electrochemical impedance spectra (EIS) of the solar cells showed that interfacial charge recombination resistance of the device based on a GUTS-4 post-treated $\mathrm{MAPbI}_{3}$ absorber film was increased by a factor of 1.15 to 2.6, depending on light illumination intensity, compared to the control $\mathrm{MAPbI}_{3}$ cell. This is consistent with results of the open-circuit voltage $\left(V_{o c}\right)$ decay and the light intensity dependent photovoltage evolution which shows device with GUTS treatment had longer charge carrier lifetime and was more ideal (ideality factor=1.25). Further characterization by Kelvin probe force microscope indicated that GUTS-4 treatment shifted the energetics of the $\mathrm{MAPbI}_{3}$ film by $\sim 100 \mathrm{meV}$ towards better energy level alignment with adjacent $\mathrm{SnO}_{2}$ electron transport layer, leading to a more favorable charge extraction process at the $\mathrm{MAPbI}_{3} / \mathrm{SnO}_{2}$ interface. As a result, the PCE of PSCs was enhanced from $14.59 \%$ to $16.37 \%$ and the hysteresis effect was mitigated.

Keywords: Perovskite solar cells; Large grains; Improved fill factor; High Efficiency; Ostwald ripening. 


\section{INTRODUCTION}

Recently, organic-inorganic lead halide perovskites have emerged as ideal materials for low-cost solution-processable, high-efficiency solar technologies. ${ }^{1}$ Solar cells based on perovskites have shown sky-rocketing progress in power conversion efficiency (PCE) within seven years of development, from $3.8 \%$ in 2009 to over $22 \%$ in early 2016, making it the most commercially attractive solar cell technology at present. ${ }^{2,3}$ The nature of am-bipolar charge transport of perovskite (perovskite materials can transport both electron and hole between cell terminals) ${ }^{4-6}$ have led to the development of planar perovskite solar cell configurations in which perovskite functions as both the light absorber and charge transport layers. The structural simplicity of the planar configuration makes it even more economically viable and commercially attractive.

It is recognized that a delicate control of the optoelectronic quality of perovskite film is of vital importance to obtain a high-efficiency solar cell, especially for planar structure. ${ }^{6,7}$ For example, pin-holes and incomplete surface coverage can result in low light absorption and low-resistance shunting paths while the high density of undesirable defects causes a high-rate of charge recombination and low charge collection efficiency. This in turn entails low photovoltaic performance of the corresponding devices. To solve this issue, methods for preparing pinhole-free, uniform and highly compact films have been developed such as the anti-solvent one-step dripping method. ${ }^{7-10}$ Fundamentally, the anti-solvent method involves in pouring of an anti-solvent onto a wet perovskite film to induce fast crystallization, resulting in formation of a smooth, fine-grained polycrystalline film which contains significant number of grain boundaries (GBs). Recent reports have suggested that, GBs in perovskite film are likely to function as: 1) centralized areas of electronic trap states and 2) pathways for ion migration. ${ }^{11-13}$ The electronic trap states not only serve as barriers for charge transport, but they also enhance non-radiative recombination, severely reducing the charge carrier life time, and thus the overall photovoltaic device performance. ${ }^{14-16}$ Possibly, the high density of GBs or electronic defects in the perovskite films prepared by typical deposition techniques, including the antisolvent-dripping method, is one of the reasons why the best performing PSCs still lags behind the theoretical Schocley-Queisser efficiency limit for a single junction solar cell. ${ }^{17}$ In addition, ion migration 
at GBs is suspected to cause current-voltage hysteresis of perovskite devices. ${ }^{18}$ As such, it is essential to reduce the number of GBs through increasing grain sizes and/or passivating the GBs of perovskite films to enable hysteresis-free high efficiency PSCs.

A variety of methods have been established to eliminate the GBs of perovskite films through the careful control of nucleation-growth rates by modification of underlying substrates ${ }^{11,19}$ or altering the chemistry of precursor solutions. ${ }^{20,21}$ Among them, methods based on tuning perovskite precursor composition seem to be the most successful. Yang et al. reported that methyammonium iodide (MAI) is an effective additive to tune the grain size of methyammonium lead tri-iodide $\left(\mathrm{MAPbI}_{3}\right)$ films from few hundred nanometer to few micrometer. ${ }^{20}$ Pursuing a different direction, Carmona et al. stated that a moderate excess of $\mathrm{PbI}_{2}$ in the $\mathrm{MAPbI}_{3}$ precursor is beneficial for obtaining large homogeneous $\mathrm{MAPbI}_{3}$ films. ${ }^{22}$ Crystal growth retardants, such as lead(II) chloride $\left(\mathrm{PbCl}_{2}\right)$ have also been shown to be an advantageous precursor additive for grain size enlargement of $\mathrm{MAPbI}_{3}$ films. ${ }^{23,24}$ Besides lead(II) halide based additives, non-halide lead source such as lead(II) thiocyanate $\left(\mathrm{Pb}(\mathrm{SCN})_{2}\right)$ were also reported to be effective for enhancing crystal domain sizes of perovskite films. ${ }^{25-29}$

Nevertheless, it is difficult to prepare high optoelectronic quality perovskite film with minimal defect densities, even with anti-solvent dripping method, and thus film post treatment is normally necessary. ${ }^{30-34}$ Among these, the method based on post treatment of $\mathrm{MAPbI}_{3}$ perovskite film using methylammonium bromide (MABr)/isopropanol was reported to lead to secondary crystallization of $\mathrm{MAPbI}_{3}$ films through an Ostwald ripening mechanism. ${ }^{32}$ The resulting $\mathrm{MAPbI}_{3}$ films have enhanced grain size, crystallinity and yielded better PCE devices. The elegance of this finding is that post-treated perovskite films are pinholefree, possessing large grain domain and low density of defects regardless of the quality of initial film. However, the $\mathrm{MAPbI}_{3}$ films prepared by the MABr-assisted Ostwald ripening process often contain broad crystal size distributions even though the film has undergone an extreme heat treatment process (i.e. $150^{\circ} \mathrm{C}$ for 10 minutes). To date, only a few Ostwald ripening-assisted precursors have been utilized for the posttreatment of perovskite films due to strict requirements for efficient coarsening in Ostwald-type ripening 
process. ${ }^{32}$ Due to this, there still remains considerable room to explore the application of Ostwald ripeningassisted for improving the quality of perovskite film for higher power conversion efficiency.

Apart from grain size enlargement, approaches for passivation of GBs and interfaces/surface of perovskite film have also been investigated. Fullerene, an electron transport layer, was found to be an effective passivating agent which diffuses along GBs to passivate the defects. ${ }^{35-37}$ Several groups have noted that $\mathrm{PbI}_{2}$ is able to passivate GBs and interfaces of perovskite films. ${ }^{21,38,39}$ These studies have shown that $\mathrm{PbI}_{2}$ mainly occupies the space along GBs of perovskite film, forming an energy barrier that hinders leakage of both electrons and holes from perovskite film which reduces recombination. Furthermore, guanidinium iodide (GuI) was also found to successfully suppressing defects at GBs of $\mathrm{MAPbI}_{3}$ films (more reference). ${ }^{40}$ The use of $(\mathrm{GuI})$ in $\mathrm{MAPbI}_{3}$ precursor solutions has proven to extend the charge carrier lifetime by a factor of ten, and thus yielding PCE exceeding $17 \%$ for planar $\mathrm{MAPbI}_{3}$ solar cell. The research showed that guanidinium ions do not incorporate in perovskite lattice, but instead, reside at the GBs of perovskite film, forming hydrogen bonds with under-coordinated iodine species and thus suppressing charge recombination. Although the benefits of $\mathrm{GuI}$ for defect mitigation in $\mathrm{MAPbI}_{3}$ films is exceptional, the final structure of Gu-based products remain unclear.

Herein, we report a new method based on treatment of $\mathrm{MAPbI}_{3}$ film using a guanidinium thiocyanate (GUTS) precursor solution. In this study, it was found that the GUTS-treatment effectively converts finedgrain nanometer-scale $\mathrm{MAPbI}_{3}$ film into micron-sized $\mathrm{MAPbI}_{3}$ perovskite film with a low density of GBs. We have also found that this GUTS-post treatment method successfully passivates the perovskite interface, which in turn significantly reduces surface charge recombination. The cooperation of these two effects enables improved performance of solar cells with less hysteresis. 


\section{EXPERIMENTAL SECTION}

\section{Materials preparation}

All materials were purchased from Sigma-Aldrich and used as received without further purification unless otherwise stated. Methylammonium lead tri-iodide $\left(\mathrm{MAPbI}_{3}\right)$ perovskite films were prepared based on Lewis acid-base adduct approach, details of which are described in the previous reports. ${ }^{9}$ ${ }^{10}$ In brief, a $\mathrm{MAPbI}_{3}$ perovskite precursor solution was prepared by dissolving $461 \mathrm{mg}$ of $\mathrm{PbI}_{2}, 159$ mg of methylammonium iodide (MAI) (Dyesol), and $78 \mathrm{mg}$ of dimethyl sulfoxide (DMSO) in 650 mg of dimethyl formamide (DMF) at room temperature, under rigorous stirring for four hours to obtain clear solution. The prepared $\mathrm{MAPbI}_{3}$ precursor solution was filtered by a syringe filter (pore size: $0.22 \mu \mathrm{m}$ ) prior to use for deposition of films. Guanidinium thiocyanate (GUTS) precursors were prepared by dissolving different amounts of GUTS ( $2 \mathrm{mg}, 4 \mathrm{mg}, 6 \mathrm{mg}, 8 \mathrm{mg}$, and $10 \mathrm{mg})$ in 1 $\mathrm{mL}$ anhydrous isopropanol (IPA). A solution for hole transport material was prepared by addition of $72.3 \mathrm{mg}$ of 2,2',7,7'-Tetrakis-(N,N-di-4-methoxyphenylamino)-9,9'-spirobifluorene (SpiroMeOTAD) (Borun New Material), $28.8 \mu \mathrm{L}$ of 4-tert-butylpyridine, and $17.5 \mu \mathrm{L}$ of Bis(trifluoromethane)sulfonimide lithium (Li-TFSI) solution (720 mg of Li-TFSI in acetonitrile) to $1 \mathrm{~mL}$ of chlorobenzene.

\section{Device fabrication}

Solar cells were fabricated using fluorine-doped tin oxide (FTO) coated glass (Nippon Electric Glass, $15 \Omega / \square$ ) as substrate which was firstly patterned through partially removal of FTO via etching with $35.5 \mathrm{wt} \% \mathrm{HCl}$ and zinc powder. The substrates were then cleaned for $20 \mathrm{mins}$ in an ultrasonic bath with an aqueous solution of Decon-90 detergent (5\%), followed by the same treatment in a mixture of acetone, isopropanol and ethanol (1:1:1, volume ratio). Prior to use, the substrates were treated with UV-Ozone for 30 mins to remove any remaining organic solvent residue. An electron transport layer based on $\mathrm{SnO}_{2}(\sim 40 \mathrm{~nm})$ was deposited via spin-coating 0.1 M solution of tin(II) chloride $(98 \%)$ in ethanol $(96 \%)$ at $3000 \mathrm{rpm}$ for $30 \mathrm{~s}$ in air. The film was then annealed in air at 
$185^{\circ} \mathrm{C}$ for 1 hour before being cleaned with UV-Ozone for 20 mins and transferred to an Ar-filled glove box. $\mathrm{A} \mathrm{MAPbI}_{3}$ layer $(\sim 400 \mathrm{~nm})$ was deposited onto the prepared $\mathrm{SnO}_{2}$ layer at $4000 \mathrm{rpm}$ for 25 s. During spin-coating, $0.5 \mathrm{~mL}$ of diethyl ether was dropped onto the center of the spinning substrate $18 \mathrm{~s}$ prior to the end of the program. The perovskite layer was then dried at $65^{\circ} \mathrm{C}$ for 2 mins. For samples treated via the GUTS methodology, $100 \mu \mathrm{L}$ of GUTS in IPA solution (2-10 $\mathrm{mg} / \mathrm{mL}$ ) was dropped on top of the perovskite film during a second spin coating cycle at $4000 \mathrm{rpm}$. The perovskite layer was then annealed at $100^{\circ} \mathrm{C}$ for 2 mins. For convenience, the $\mathrm{MAPbI}_{3}$ films with treatments of $2 \mathrm{mg} / \mathrm{mL}, 4 \mathrm{mg} / \mathrm{mL}, 6 \mathrm{mg} / \mathrm{mL}, 8 \mathrm{mg} / \mathrm{mL}$ and $10 \mathrm{mg} / \mathrm{mL}$ GUTS in IPA are abbreviated as GUTS-x-MAPbI 3 , where $\mathrm{x}=2,4,6,8$ and 10. The hole-transport layer $(\sim 200 \mathrm{~nm})$ was deposited from the prepared Spiro-OMeTAD solution onto the as-prepared perovskite layer at $4000 \mathrm{rpm}$ for $30 \mathrm{~s}$. The device fabrication was finished by deposition of a $100 \mathrm{~nm}$ layer of gold for use as a back contact on the prepared sample via an e-beam evaporation process operating at $10^{-6}$ torr pressure.

\section{Characterization}

The top-view and cross-sectional scanning electron microscopy (SEM) images of the samples were obtained using a field emission scanning electron microscope (FSEM JOEL 7001F) at an acceleration voltage of $5 \mathrm{kV}$. The UV-visiable absorbance spectrum was measured with a UVvisible spectrometer (Cary 50). Crystal structure of the perovskite film deposited on FTO-glass substrate was determined by X-ray diffraction (Rigaku SmartLab) with a monochromatic $\operatorname{CuK} \alpha(\lambda=0.154 \mathrm{~nm})$ as a radiation source. A scan rate of $1.5^{\circ} /$ minute and step size of $0.02^{\circ}$ was used in the XRD measurement. The performance of perovskite devices was measured under irradiation of $100 \mathrm{~mW} / \mathrm{cm}^{2}$ (AM1.5, $1 \mathrm{sun}$ ) provided by a solar simulator (Oriel Sol3A, Newport) equipped with $450 \mathrm{~W}$ Xenon lamp. IPCE measurement was conducted by quantum efficiency system (IQE 200B, Newport) under AC mode. Electrochemical impedance spectroscopy (EIS) of the PSCs was performed in a frequency range from $1 \mathrm{MHz}$ to $100 \mathrm{mHz}$ using an electrical workstation (VSP BioLogic Science Instruments) under open-circuit condition with different light 
illumination intensities. An AC voltage with a perturbation amplitude of $20 \mathrm{mV}$ was applied on the device in the (EIS) measurement. Scanning Kelvin Probe Force Microscopy (KPFM) (Oxford instrument, Asylum Research) was performed on the prepared perovskite film in ambient conditions using NSG-03 Pt coated cantilever at room temperature. Work function of the cantilever was measured using HOPG standard sample.

The open-circuit voltage decay measurements were performed by monitoring the open-circuit voltage ( $\left.V_{o c}\right)$ of PSC as a function of time in dark with an electrochemical workstation (BioLogic). The $V_{o c}$ of the cell was generated using a white light LED with illumination intensity equivalent to 0.15 sun (illumination time: $\sim 2 \mathrm{~s}$ ). The open-circuit voltage decay (OCVD) was recorded when the white LED was turned off.

The light intensity dependence of open-circuit voltage $\left(V_{o c}\right)$ measurement was carried out by measuring $J-V$ plots of the solar cell under different illumination intensities generated by the solar simulator. The light intensities were controlled by using neutral density optical filters with transmittance of $1 \%, 11 \%, 19 \%, 30 \%$ and $55 \%$.

The stability of the PSCs was tested by monitoring the efficiency of un-encapsulated PSCs which were stored in a desiccator (relative humidity $\sim 33-35 \%$ ) in dark. The performance of the device was measured every 3 days in ambient condition with relative humidity of 40-60\%. 


\section{Results and discussion}

Figure 1(a)-(f) illustrates the top-view scanning electron microscopy (SEM) images of GUTS-X-MAPbI 3 perovskite films with $\mathrm{x}=0,2,4,6,8,10$, respectively. In accordance to the previous reports, ${ }^{9,}{ }^{10} \mathrm{MAPbI}_{3}$ film synthesized by our one-step Lewis acid-base adduct method is pinhole-free, highly compact with crystallite sizes ranging from $100 \mathrm{~nm}$ to $500 \mathrm{~nm}$ (Fig. 1a). When $\mathrm{MAPbI}_{3}$ films were treated with GUTS-2 precursor ( $2 \mathrm{mg} / \mathrm{mL}$ GUTS in isopropanol (IPA)), larger grains with domain size up to $800 \mathrm{~nm}$ were observed while the $\mathrm{MAPbI}_{3}$ film remains uniform and compact (Fig. 1b). Upon increasing the concentration of GUTS to $4 \mathrm{mg} / \mathrm{mL}$ (Fig. 1c), clear evidence of grain growth is seen with most grains exceeding $1 \mu \mathrm{m}$. Compared to the pristine $\mathrm{MAPbI}_{3}$ film, the lateral crystallite size of GUTS-4-MAPbI 3 film is five-folds larger, suggesting the effectiveness of this simple post processing procedure. As a general indication, the larger the perovskite film crystals, the higher the solar cell performance is expected because perovskite films with larger grains have lower numbers of GBs which act as barriers for charge transport between the cathode and anode in PCS. ${ }^{11,12,28}$ With further increment of the GUTS concentration to $6 \mathrm{mg} / \mathrm{mL}, 8 \mathrm{mg} / \mathrm{mL}$ and $10 \mathrm{mg} / \mathrm{mL}$, even larger grain sizes are observed $(\sim 2 \mu \mathrm{m}$ in average with GuTS-10 treated film). However, pronounced contrast along GBs and surface of $\mathrm{MAPbI}_{3}$ film are observed, which suggests formation of secondary phases. The amount of secondary phases increased as the concentration of GUTS increased, which is more clearly shown at lower magnification SEM images (Fig. S1). Furthermore surficial wrinkles are also found on the $\mathrm{MAPbI}_{3}$ grains as the concentration of GUTS exceeded $6 \mathrm{mg} / \mathrm{mL}$ (Fig. 1df). The appearance of these wrinkled textures is likely induced by strain due to massive $\mathrm{MAPbI}_{3}$ grain coarsening and/or competitive grain growth of $\mathrm{MAPbI}_{3}$ crystals and secondary phases, ${ }^{10}$ which may lead to high surface roughness. 

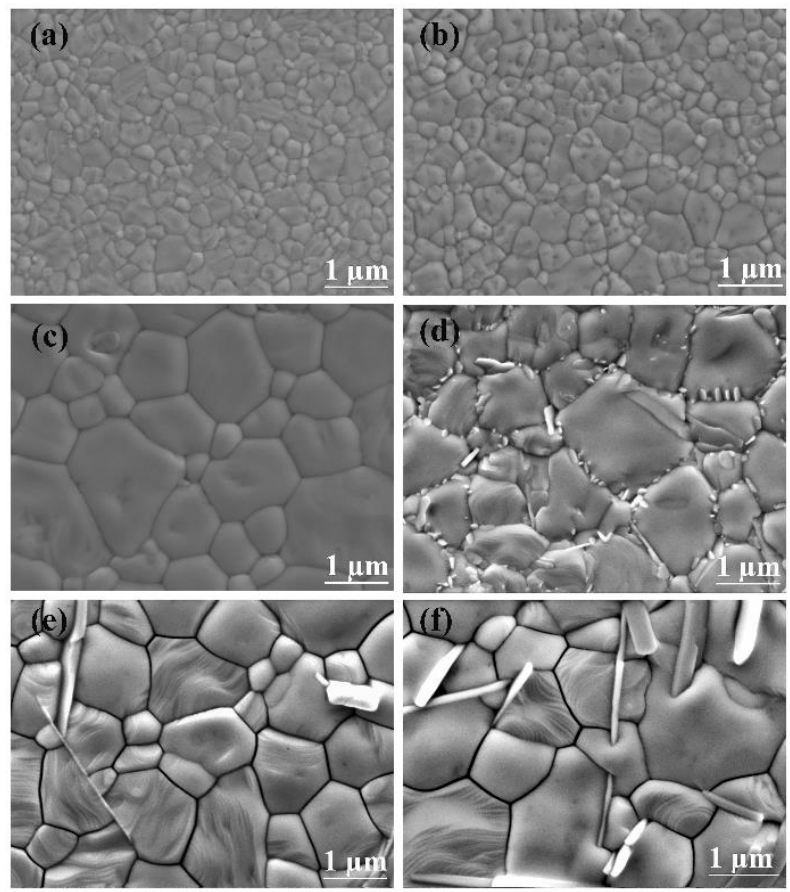

Fig. 1 Top-view SEM images of $\mathrm{MAPbI}_{3}$ films. (a) Control $\mathrm{MAPbI}_{3}$ film and the film treated with different concentrations of GUTS/IPA solution (b) $2 \mathrm{mg} / \mathrm{mL}$, (c) $4 \mathrm{mg} / \mathrm{mL}$, (d) $6 \mathrm{mg} / \mathrm{mL}$, (e) $8 \mathrm{mg} / \mathrm{mL}$, (f) $10 \mathrm{mg} / \mathrm{mL}$.

Before further characterization of optoelectronic properties of the $\mathrm{MAPbI}_{3}$ film, we first investigated the fundamental reason for the significant morphological change in the films. With the knowledge that IPA is capable of dissolving $\mathrm{MAPbI}_{3}$ via MAI-extracting (1), ${ }^{41,42}$ we presume that this extraction is the initial stages of Ostwald ripening which could be the potential origin for the above morphological change.

$$
\mathrm{CH}_{3} \mathrm{NH}_{3} \mathrm{PbI}_{3}(\mathrm{IPA}) \leftrightarrow \mathrm{CH}_{3} \mathrm{NH}_{3} \mathrm{I}+\mathrm{PbI}_{2}
$$

According to the Ostwald ripening process, once the GUTS/IPA solution is introduced to the surface of $\mathrm{MAPbI}_{3}$ film, unstable small $\mathrm{MAPbI}_{3}$ crystals with high surface energy will be partially dissolved into the IPA, giving up their mass so that large stable crystals can grow. ${ }^{32,43}$ In this mechanism, the dissolution/denucleation rate of the unstable small $\mathrm{MAPbI}_{3}$ crystals (depending on solubility capacity of solvent used) is extremely crucial because it determines the growth rate coefficient of stable large $\mathrm{MAPbI}_{3}$ crystals. ${ }^{44}$ In other words, the higher rate of de-nucleation/dissolution, the higher the rate of crystal growth, and thus larger crystal size could be obtained according to the following equation: 


$$
\mathrm{Z}\left(\mathrm{D}_{\mathrm{N}}, \mathrm{G}\right)=1.1\left(\mathrm{D}_{\mathrm{N}} \times \mathrm{G}\right)^{-0.5}
$$

Where $\mathrm{Z}\left(\mathrm{D}_{\mathrm{N}}, \mathrm{G}\right)$ is the number of crystals per unit area, which is inversely proportional to the crystal size, $D_{N}$ is de-nucleation rate of unstable small crystals and $G$ is growth rate of stable large crystals.

To verify our hypothesis, we examined the effect of IPA-only post treatment on the morphology of $\mathrm{MAPbI}_{3}$ film. We found that marginal grain size enhancement was observed with the $\mathrm{MAPbI}_{3}$ film treated with IPA (Fig. S2) which is consistent with a recent study. ${ }^{32}$ We infer that the extremely low solubility of $\mathrm{MAPbI}_{3}$ in IPA leads to a low rate of de-nucleation/dissolution of unstable small $\mathrm{MAPbI}_{3}$ crystals, and thus inefficient coarsening process. It has been reported by Yang et al., that methylammonium bromine (MABr) is able to tackle the problem as it favours the dissolution reaction (1). ${ }^{32}$ However, as stated, the intercalation of $\mathrm{MABr}$ and/or the $\mathrm{I} / \mathrm{Br}$ exchange reaction could competitively take place, inhibiting the dissolution reaction, which in turn restricts effective Oswald ripening of $\mathrm{MAPbI}_{3}$ film.

Similar to $\mathrm{Br}^{-}$anion, $\mathrm{SCN}^{-}$anion has stronger interaction with $\mathrm{Pb}^{2+}$ cation compared with $\mathrm{I}^{-}$anion, thus one can expect that GU-SCN/IPA may follow the same grain coarsening mechanism as does by MABr/IPA. ${ }^{45}$ However, as shown in Fig. S3, compared to MABr/IPA treatment, a $\mathrm{MAPbI}_{3}$ film prepared by GUTS/IPA treatment is smoother with grain sizes two-folds larger on average and a narrower grain size distribution. In addition, micron-sized $\mathrm{MAPbI}_{3}$ grains were easily formed by using the GUTS post treatment even without heat treatment (Fig. S4), indicating that the Ostwald ripening process enabled by the GUTS/IPA treatment is very effective. More interestingly, there is no concentration window for GUTS/IPA which is required to control the size of $\mathrm{MAPbI}_{3}$ grains. Instead, the higher of the concentration of GUTS/IPA is used, the larger grain is observed (Fig 1 and Fig. S5). The above observations lead us to conclude that besides the dissolution-assisted effect of GUTS (as similar to MABr), there must be another source that aids the grain growth. There is a possibility that there is a reaction of GUTS/IPA and MAPbI 3 as follows:

$$
\mathrm{CH}_{3} \mathrm{NH}_{3} \mathrm{PbI}_{3}+\mathrm{Gu}-\mathrm{SCN} \rightarrow\left(\mathrm{GuI}(\mathrm{s})+\mathrm{PbI}_{2}(\mathrm{~s})\right)+\left(\mathrm{CH}_{3} \mathrm{NH}_{2}(\mathrm{~g})+\mathrm{HSCN}(\mathrm{g}) \uparrow\right)
$$


The unstable HSCN (gas) is probably expelled from the film rapidly ${ }^{28}$ since we could not detect any observable signal of sulfur by X-ray photoelectron microscopy (XPS), inductively coupled plasma spectroscopy (ICP-MS) and Fourier transform infrared spectroscopy (FTIR) (not shown here). The produced $\mathrm{PbI}_{2}$ and $\mathrm{GuI}$ and/or a compound formed by them $\left((\mathrm{GuI})_{\mathrm{x}}\left(\mathrm{PbI}_{2}\right)_{\mathrm{y}}\right)$ accumulates at the surface and GBs of $\mathrm{MAPbI}_{3}$ film as the secondary phases according to Fig. 1e-f. It is very likely that the as-formed $\mathrm{CH}_{3} \mathrm{NH}_{2}$ (MA) gas can dissolve $\mathrm{MAPbI}_{3}$ crystal more efficiently than IPA, as suggested by previous reports. ${ }^{33,46-49}$ We therefore propose that the formed MA (gas) enhances the rate of de-nucleation and increases the solubility of unstable small $\mathrm{MAPbI}_{3}$ crystals which in turn facilitates the grain coarsening. Compared to conventional method of Ostwald ripening, the dissolution of small-sized $\mathrm{MAPbI}_{3}$ crystals enabled by GUTS/IPA post treatment in this work is extremely fast and effective. As a result, the process is easier and more efficient to form large grain in the $\mathrm{MAPbI}_{3}$ film. A comparison is outlined in Fig. 2.

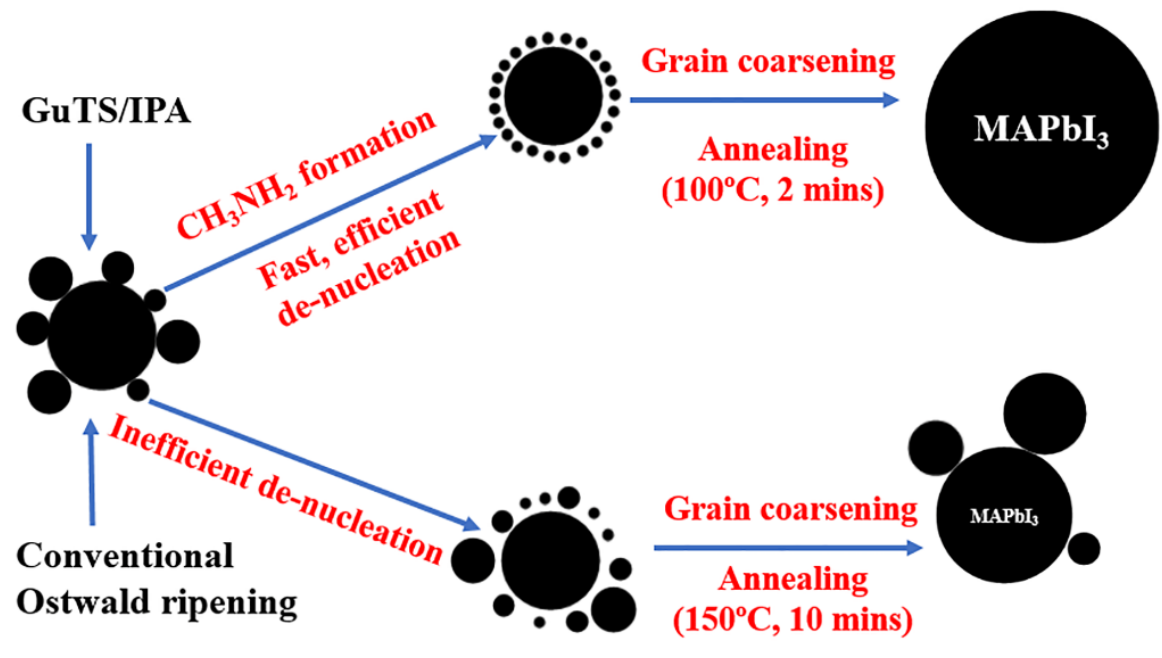

Fig. 2 Schematic illustration of Ostwald ripening process for the $\mathrm{MAPbI}_{3}$ perovskite crystal growth assisted by GUTS in this work and by conventional method.

We have further found that incorporating GUTS into $\mathrm{MAPbI}_{3}$ precursor solution does slightly enlarge domain size of $\mathrm{MAPbI}_{3}$ films as illustrated in Fig. S6a-d. However, compared to GUTS post-treated $\mathrm{MAPbI}_{3}$ film, those with GUTS additive in perovskite precursor are two-folds smaller in terms of domain size (Fig. S6-d versus Fig. 1c). Besides, adding GUTS additives to the $\mathrm{MAPbI}_{3}$ precursor leads to the formation of a considerable impurities on surface of $\mathrm{MAPbI}_{3}$ film as shown in Fig. S6(b, c, d), reducing the 
optoelectronic quality of the films. We therefore propose that GUTS-assisted Ostwald ripening posttreatment could be the best procedure for fabricating $\mathrm{MAPbI}_{3}$ film with the optimal morphology.

The absorption spectra of $\mathrm{MAPbI}_{3}$ films prepared from different GUTS concentrations (Fig. S7) show characteristic absorption onset at around $770 \mathrm{~nm}$ regardless of GUTS concentration, indicating that the band gap of $\mathrm{MAPbI}_{3}$ is not affected by GUTS treatment. Below $4 \mathrm{mg} / \mathrm{mL}$ GUTS in IPA, the $\mathrm{MAPbI}_{3}$ film has slightly higher light absorption coefficient than the pristine one, suggesting an improved film crystallinity. Beyond that, the absorbance of $\mathrm{MAPbI}_{3}$ films is reduced which can be ascribed to the formation of a substantial amount of secondary phases (as shown in Fig. 1d-f).

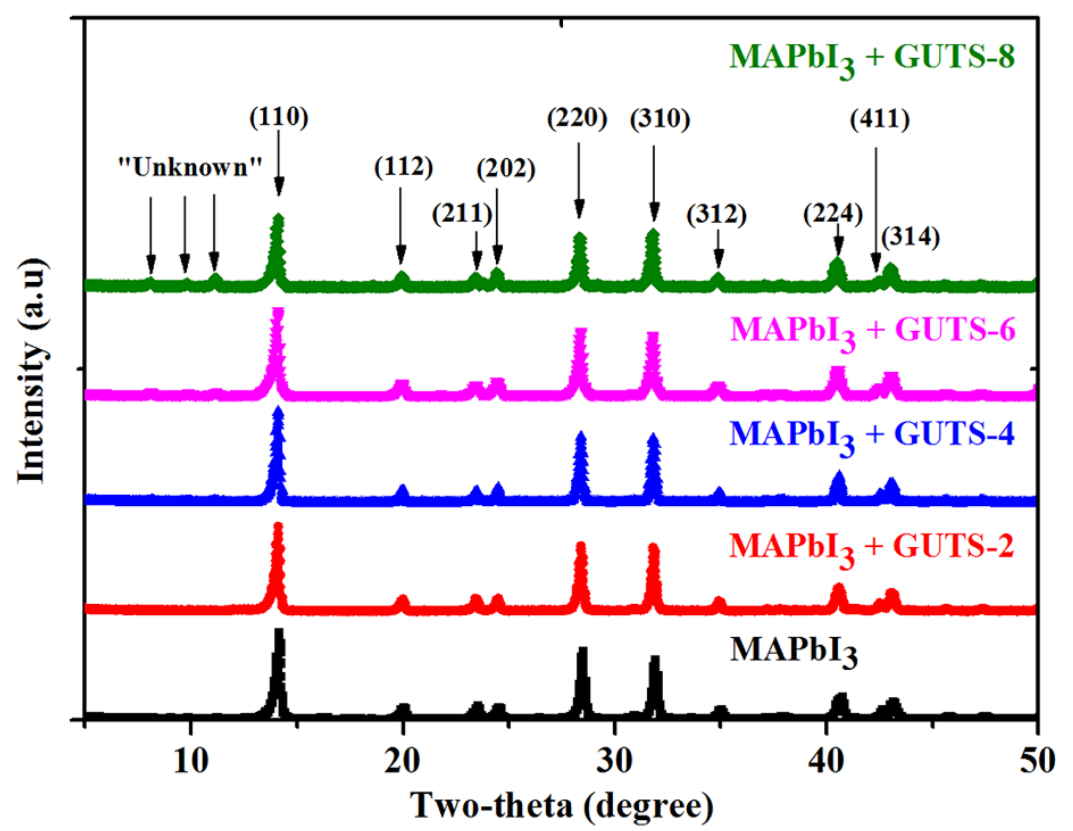

Fig. 3 XRD patterns of $\mathrm{MAPbI}_{3}$ films with and without GUTS treatment.

$\mathrm{X}$-ray diffraction (XRD) was used to structurally characterize the material phases in the $\mathrm{MAPbI}_{3}$ films with and without GUTS-treatment (Fig. 3). As indexed in Fig. 3, the main peaks of all the films can be well assigned to the reflection of $\mathrm{MAPbI}_{3}$. It should be noted that the peak intensity ratio between (220) and (310) plane changes as concentration of GUTS increases, indicating the change in growth rate of the $\mathrm{MAPbI}_{3}$ crystals at different crystallographic directions. This change could also be associated with the formation of secondary phases, which might alter crystal growth rate at particular direction. In addition, weak diffraction peaks at $8.12^{\circ}, 9.82^{\circ}$, and $11.2^{\circ}$ are observed when the concentration of GUTS for post 
treatment is over $6 \mathrm{mg} / \mathrm{mL}$, which should be assigned to the observed secondary phases observed in topview SEM images (Fig. 1d-f).

To identify these unknown peaks, we collected XRD patterns of Gu-SCN (powder), GuI (powder) and "GuPbI 3 " films (Fig. S9) because they are most likely the by-products of the reaction (3). A yellow GuPbI 3 film was prepared by spin-coating a precursor of $\mathrm{GuI}: \mathrm{PbI}_{2}: \mathrm{DMSO}(1: 1: 1$, molar ratio) in DMF followed by annealing at $100^{\circ} \mathrm{C}$ for 2 mins. It is worth highlighting that no peak from Gu-SCN was found in the diffraction patterns of GUTS-treated $\mathrm{MAPbI}_{3}$, indicating that Gu-SCN was completely consumed in the reaction (3) with $\mathrm{MAPbI}_{3}$. In addition, the unknown peaks do not match any diffraction patterns of GuI or "GuPbI${ }_{3}$ " phases either, suggesting that the by-products induced by reaction (3) (probably GuI and $\mathrm{PbI}_{2}$ ) combined with each other to form intermediate phases $(\mathrm{GuI})_{\mathrm{x}}\left(\mathrm{PbI}_{2}\right)_{\mathrm{y}}$, located at the $\mathrm{GBs}$ or/and the surface of $\mathrm{MAPbI}_{3}$ film, in accordance with previous observation. ${ }^{40}$ According to Ref 40 , a tiny amount of the intermediate phases are not harmful to the resulting device performance, instead they could passivate the GBs/surface defects. We therefore have not intentionally excluded the subtle amount of the intermediate phases in the $\mathrm{MAPbI}_{3}$.

Having shown that micron-sized $\mathrm{MAPbI}_{3}$ films could be easily obtained through manipulation of the concentration of GUTS in the post treatment process, we proceed to integrate these films into solar cells. The performance of these $\mathrm{MAPbI}_{3}$ devices is compared and listed in Table 1. 
Table 1: Characteristic photovoltaic parameters of $\mathrm{MAPbI}_{3}$ solar cells with different concentration of GUTS in the post treatment process.

\begin{tabular}{lcccccc}
\hline Cell & PCE & $J_{s c}$ & $V_{o c}$ & $F F$ & $R_{s}$ & $R_{s h}$ \\
& $(\%)$ & $\left(\mathrm{mA} / \mathrm{cm}^{2}\right)$ & $(\mathrm{V})$ & $(\%)$ & $\left(\Omega / \mathrm{cm}^{2}\right)$ & $\left(\mathrm{k} \Omega / \mathrm{cm}^{2}\right)$ \\
\hline Reference & $12.7 \pm 1.8$ & $20.7 \pm 0.8$ & $1.02 \pm 0.03$ & $60 \pm 5$ & $53 \pm 5$ & $1.5 \pm 0.7$ \\
& & & & & & \\
GUTS-2 & $13.5 \pm 1.5$ & $20.7 \pm 0.5$ & $1.04 \pm 0.03$ & $63 \pm 4$ & $44.0 \pm 3.3$ & $3.4 \pm 0.9$ \\
& & & & & & \\
GUTS-4 & $15.2 \pm 0.9$ & $21.1 \pm 0.3$ & $1.06 \pm 0.0 .02$ & $68 \pm 3$ & $33 \pm 2.9$ & $9.1 \pm 1.1$ \\
& & & & & & \\
GUTS-6 & $13.9 \pm 1.1$ & $20.6 \pm 0.38$ & $1.04 \pm 0.03$ & $65 \pm 2$ & $38.1 \pm 3.8$ & $5.2 \pm 1.4$ \\
& & & & & & \\
GUTS-8 & $10.9 \pm 2$ & $19.5 \pm 0.45$ & $0.97 \pm 0.05$ & $58 \pm 6$ & $62.8 \pm 6.6$ & $2.1 \pm 1.7$ \\
\hline
\end{tabular}

When the $\mathrm{MAPbI}_{3}$ absorber layer was post treated with GUTS/IPA with concentration up to 4 $\mathrm{mg} / \mathrm{mL}$, the average power conversion efficiency (PCE) of the solar cells increases by nearly $20 \%$, from $12.7 \pm 1.8 \%$ to $15.2 \pm 0.9 \%$, mainly due to the increase of open-circuit voltage ( $V_{o c}$ ), from average $1.02 \pm 0.03 \mathrm{~V}$ to average $1.06 \pm 0.0 .02 \mathrm{~V}$, and fill-factor $(F F)$, from $60 \pm 5 \%$ to $68 \pm 3 \%$ (Table 1). These results are consistent with the observed reduction of the series resistance $\left(R_{s}\right)$ by $37 \%$, and the significant increase of shunt resistance $\left(R_{s h}\right)$ by six-folds of the devices (Table 1). The lower $R_{s}$ implies the perovskite film has lower inter-particle contact resistance, higher internal film conductivity and better contacts with selective charge transport layers, while the larger $R_{s h}$ indicates the greater surface and GBs passivation. ${ }^{10,50}$ In addition, slightly higher current densities are also witnessed as the GUTS precursor concentration increases, which is consistent with the UV-visible light absorption spectrum (Fig. S7 and Fig. S8). However, further increase of the GUTS content up to $8 \mathrm{mg} / \mathrm{mL}$ leads to a dramatic reduction of all photovoltaic parameters even though grain size of the $\mathrm{MAPbI}_{3}$ film was increased (Table 1). This is probably related to the formation of large quantities of secondary phases in the film and the increase in the roughness of top surface of the perovskite film as shown in Fig. 1d-e), which are believed to not only reduce the light absorption 
of $\mathrm{MAPbI}_{3}$ film (Fig. S7), but also cause current leakage, resulting in low solar cell performance. The above SEM, XRD, UV-vis absorbance and PCE data suggest that the best-performing device (GUTS-4-MAPbI 3 based solar cell, $15.2 \pm 0.8 \%$ ) is only enabled by a synergetic effect of $\mathrm{MAPbI}_{3}$ film morphology, crystallinity and the amount of incorporated secondary phases. In the next section, we will provide more insights into the effect of GUTS-4 treatment on the photovoltaic performance and electronic properties of the resultant solar cells.
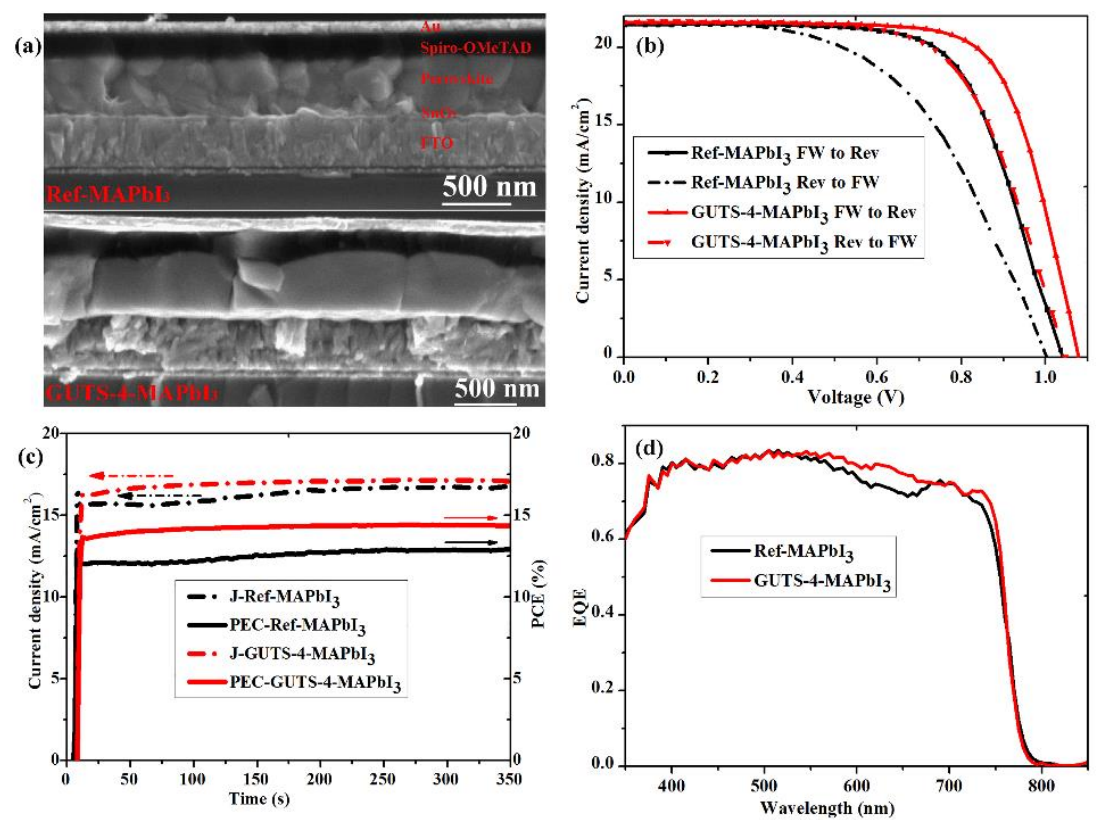

Fig. 4 (a) Cross-sectional SEM images of the completed pristine $\mathrm{MAPbI}_{3}$ and GUTS-4-MAPbI 3 solar cells; (b) $J$ - $V$ curves of $\mathrm{MAPbI}_{3}$ solar cells with and without GUTS-4 treatment, under reverse and forward voltage scan; (c) stabilized photocurrent measurement at a bias voltage $(0.78$ $\mathrm{V}$ for the pristine $\mathrm{MAPbI}_{3}$ device and $0.85 \mathrm{~V}$ for the GUTS-4-MAPbI 3 device) at maximum power point and stabilized power output under 1 sun light illumination; and (d) corresponding IPCE spectra.

Fig. 4a shows the detailed cross-sectional SEM of n-i-p planar solar cell with Ref-MAPbI 3 (top) and with GUTS-4-MAPbI 3 (bottom) absorber layer. In general, both cells consist of a $\mathrm{MAPbI}_{3}$ absorber $(\sim 400 \mathrm{~nm})$ inserted between a $\mathrm{SnO}_{2}$ electron transport layer $(\sim 40 \mathrm{~nm})$ and a SpiroOMeTAD based hole transport layer ( 200 nm with current collector of FTO glass and gold. As 
illustrated, unlike the Ref-MAPbI 3 layer which comprises of grains with variable sizes, the GUTS4- $\mathrm{MAPbI}_{3}$ layer is consisted of a monolithic $\mathrm{MAPbI}_{3}$ layer, attesting the low density of GBs/defects, and thus superior solar cell performance.

The significant reduction of GBs/defects within the $\mathrm{MAPbI}_{3}$ film leads to a $12.2 \%$ improvement in the performance of the champion devices (Fig. 4b). In particular, the Ref-MAPbI 3 device shows a maximum PCE of $14.59 \%(11.5 \%)$, with a $V_{o c}$ of $1.041 \mathrm{~V}(1.0 \mathrm{~V})$, a $J_{s c}$ of $21.46 \mathrm{~mA} / \mathrm{cm}^{2}(21.5$ $\mathrm{mA} / \mathrm{cm}^{2}$ ) and $F F$ of $65 \%(53 \%)$ under reverse (forward) scan respectively. In contrast, the GUTS4- $\mathrm{MAPbI}_{3}$ solar cell produced a PCE $16.37 \%(14.21 \%)$, with a $V_{o c}$ of $1.077 \mathrm{~V}(1.043 \mathrm{~V})$, a $J_{s c}$ of $21.6 \mathrm{~mA} / \mathrm{cm}^{2}\left(21.63 \mathrm{~mA} / \mathrm{cm}^{2}\right)$ and $F F$ of $70.4 \%(65 \%)$ under a similar measurement protocol. The performance enhancement extracted from $J$ - $V$ curves is also in line with the stabilized PCE shown in Fig. 4c, where the stabilized PCE of the $\mathrm{MAPbI}_{3}$ cell is raised by $11.6 \%$ (from $\sim 12.9 \%$ to $~ 14.5 \%$ ) with GUTS-4 post treatment. More interestingly, along with device performance enhancement, the degree of current voltage hysteresis is also suppressed with value decreases from $21 \%$ of Ref$\mathrm{MAPbI}_{3}$ solar cell to only $13 \%$ of GUTS-4-MAPbI 3 counter-part.

The Ref-MAPbI 3 cell exhibits a high external quantum efficiency (EQE) (over 70\%) across a broad wavelength range from $400 \mathrm{~nm}$ to $750 \mathrm{~nm}$, with the maximum EQE value of $\sim 83 \%$ at $\sim 500 \mathrm{~nm}$ and a depression around $650 \mathrm{~nm}$ (Fig. 4d, black curve). The depression in EQE spectrum is common for planar $\mathrm{MAPbI}_{3}$ thin-film solar cell, possibly due to the light-field interference associating with short charge carrier lifetime of the material. ${ }^{51}$ Remarkably, this depressed region is greatly filled up when the $\mathrm{MAPbI}_{3}$ absorber was treated with GUTS-4 as shown in Fig. 4d (red curve), indicating an improvement in charge carrier lifetime. As a result, the integrated current density of GUTS-4$\mathrm{MAPbI}_{3}$ cell is greater than the Ref-MAPbI 3 cell $\left(19.3 \mathrm{~mA} / \mathrm{cm}^{2} \mathrm{vs} 18.8 \mathrm{~mA} / \mathrm{cm}^{2}\right.$, respectively), which is consistent with the $J_{s c}$ obtained in the $J-V$ measurement.

Since the main enhancement of device performance are $V_{o c}$ and $F F$, owing to the plunge of the series resistance and the soar of shunt resistance of the device (Table 1), we speculate that the GUTS 
post treatment probably enhances the electronic properties of the perovskite film towards accelerating the charge transport rate and reducing charge recombination rate. Aiming to interpret the dynamics of charge transfer and recombination in the solar cell devices and to verify this hypothesis, electrochemical impedance spectroscopy (EIS) measurements were conducted at opencircuit condition $\left(\sim V_{o c}\right.$ bias) with various light illumination intensities. ${ }^{52}$

The EIS spectrum shows two semi-circles in the Nyquist plots. The EIS spectrum can be well-fitted using the equivalent circuit shown in Fig. 5a (bottom right). In the equivalent circuit, the capacitive element, $C_{g}$, at high-frequency region, represents the dielectric properties of the perovskite absorber layer while the resistive element, $R_{3}$, is associated with the transport resistance of electron along the perovskite layer interface. $C_{s}$ and $R_{l}$ obtained at low-frequency region correspond to the properties of perovskite interfaces. More specifically, $C_{s}$ serves as ionic accumulation capacitance (in dark) or electronic accumulation capacitance (under light illumination) at electrode interfaces, while $R_{l}$ coupled with $R_{3}$ determines surface recombination resistance. ${ }^{52-54}$ The extracted information from the EIS fitting for both types of devices shows that the bulk capacitance, $C_{g}$, is unchanged regardless of light illumination intensities but the interfacial charge accumulation capacitance, $C_{s}$, increases linearly with the illumination intensity (Fig. 5b), while the resistive parameters follow the inverse trend with the illumination intensity (Fig. $5 \mathrm{c}$ ).

It is found that, compared to the Ref-MAPbI 3 solar cell, the interfacial capacitance, $C_{s}$, of the GUTS-4$\mathrm{MAPbI}_{3}$ is slightly higher under light illumination, indicating a slightly higher level of electronic accumulation or higher carrier density at electrode interface. It has been reported that $V_{o c}$ of perovskite solar cell follows the trend with the $C_{s}$ because under light illumination, the $C_{s}$ can be proportionally associated with the density of minority carriers at perovskite interface. ${ }^{54}$ The EIS result observed in the darkness shows that both devices have similar $C_{s}$, implying the same level of ionic accumulation at perovskite interface (Fig.S10 and Table 1, supplementary). This result also suggests that the higher carrier density at $\mathrm{SnO}_{2} /$ perovskite interface (the perovskite/Spiro-OMeTAD interface can be regarded as ohmic contact) of the GUTS-4-MAPbI 3 cell could be due to the longer carrier lifetime. This interpretation of the $C_{s}$ is in good agreement with the slight increase of open-circuit voltage observed with the GUTS-4-MAPbI 3 samples. 

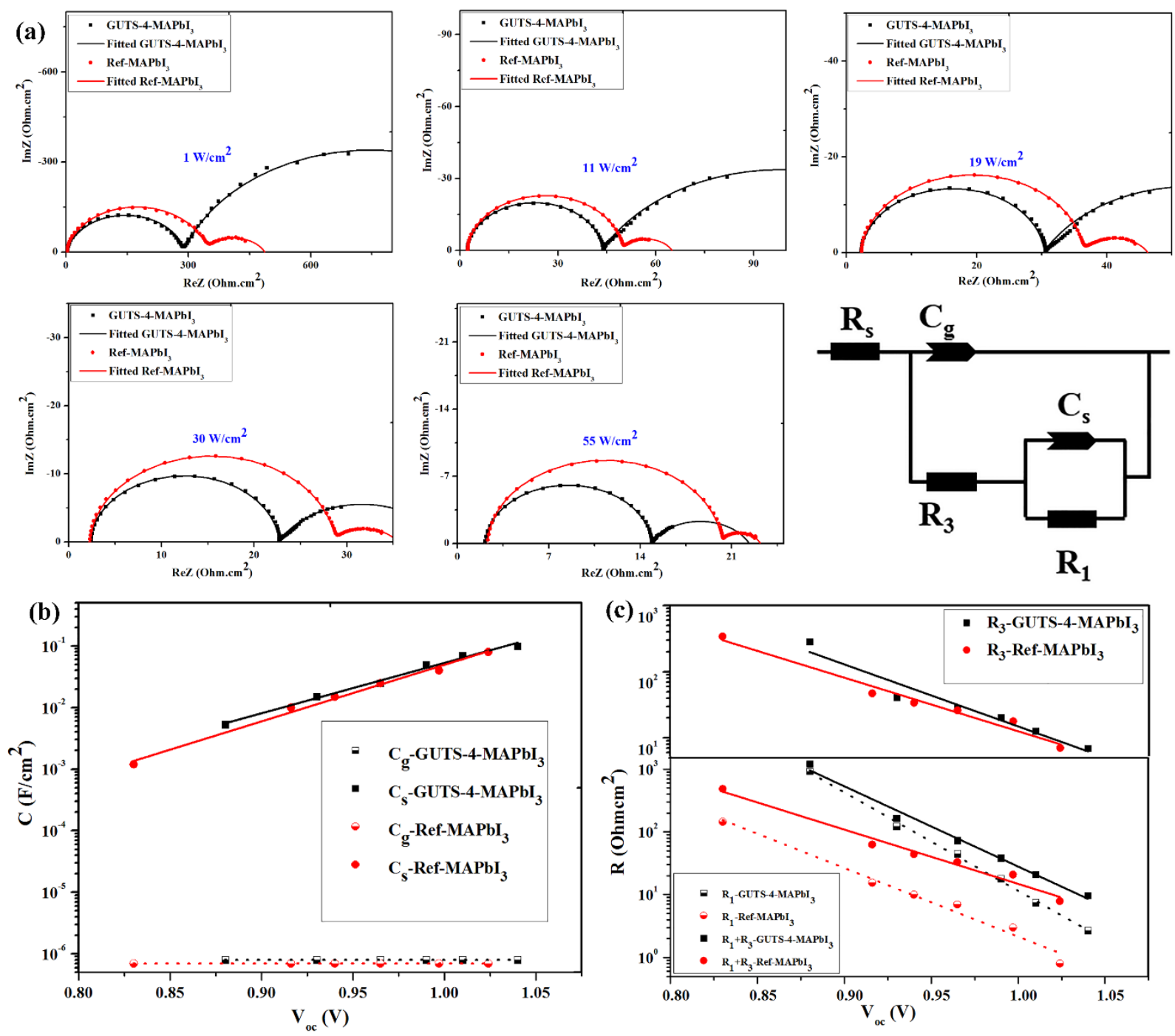

Fig. 5 (a) Nyquist plots of Ref-MAPbI 3 solar cell (circle red) and fitting (red line), and GUTS-4$\mathrm{MAPbI}_{3}$ (square black) and fitting (black line) under various light illumination intensities; and equivalent circuit (bottom right). (b) Extracted capacitance and (c) resistance.

Fig. 5c illustrates that the resistance, $R_{3}$, of the GUTS-4-MAPbI 3 solar cell is always smaller than that of the reference cell and the ratio of the $\mathrm{R}_{3}$ of the latter to the former is in the range of 1.01 and 1.29 . For example, at $1 \mathrm{~mW} / \mathrm{cm}^{2}$, the ratio is $\sim 1.2$ while at $11 \mathrm{~mW} / \mathrm{cm}^{2}, 19 \mathrm{~mW} / \mathrm{cm}^{2}, 30 \mathrm{~mW} / \mathrm{cm}^{2}, 55 \mathrm{~mW} / \mathrm{cm}^{2}$ and $100 \mathrm{~mW} / \mathrm{cm}^{2}$ illumination intensities, this value is $1.15,1.21,1.29,1.4$ and 1.01, respectively (Fig. 5c). The results in turn indicate that the GUTS-4-MAPbI ${ }_{3}$ film has lower bulk resistance and better contact with $\mathrm{SnO}_{2}$ layer than the pristine $\mathrm{MAPbI}_{3}$ film. Combining this to the fact that the $\mathrm{MAPbI}_{3}$ film with GUTS-4 treatment has much less GBs compared to the reference $\mathrm{MAPbI}_{3}$ film (Fig. 1a, c), we conclude that, the GBs probably serve as barriers for charge transport (in both the bulk and the perovskite interfaces). Once 
these barriers are eliminated, charge carrier can transport to $\mathrm{SnO}_{2}$ more efficiently. However, compared to the reference cell, the GUTS-4-MAPbI 3 cell has higher low frequency resistance, $R_{l}$, (Fig. 5c). Interestingly, the surface recombination resistance which is the sum of $R_{1}$ and $R_{3}, R_{1}+R_{3}$, of the GUTS-4-MAPbI device is larger than the pristine sample, being consistent with the enhanced device performance (Table 1). For instance, compared to the Ref-MAPbI ${ }_{3}$ device, the surface recombination resistance of the GUTS-4$\mathrm{MAPbI}_{3}$ counter-part is $\sim 2.5$-folds, 2.6-folds, 1.66-folds, 1.15-folds and 1.23-folds larger as light illumination intensity increased from $1 \mathrm{~mW} / \mathrm{cm}^{2}$ to $100 \mathrm{~mW} / \mathrm{cm}^{2}$, respectively (Fig. 5c). The above EIS results indicate that the trap-related recombination is significantly suppressed in GUTS-4-MAPbI $\mathrm{film}_{3}$, and its surface is efficiently passivated compared to the Ref- MAPbI 3 .
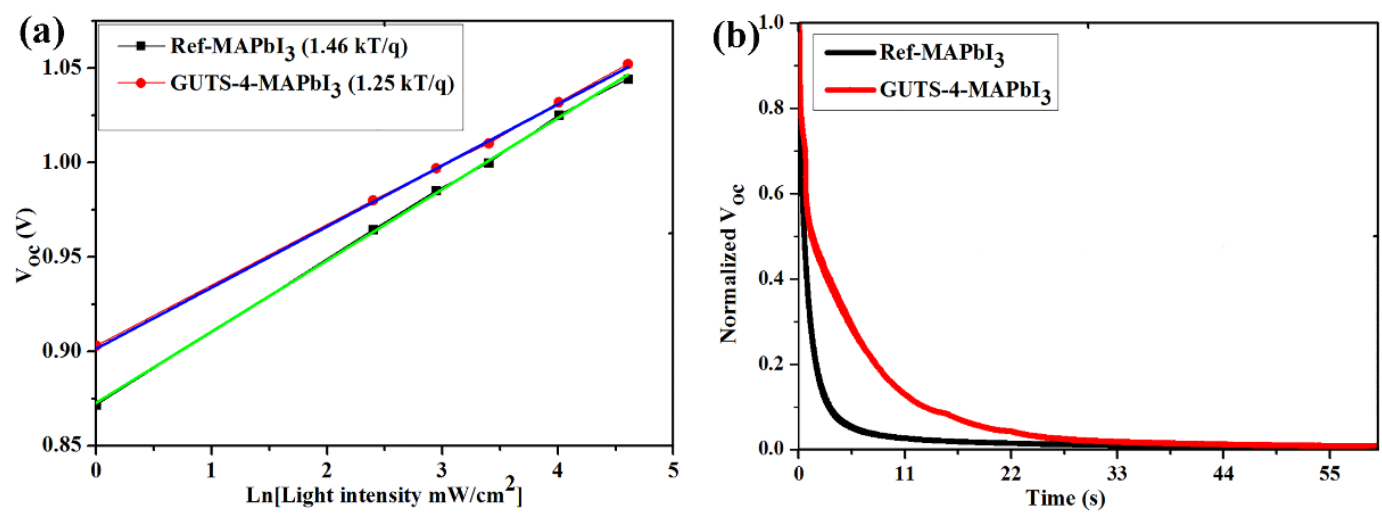

Fig. 6 Open-circuit voltage $\left(V_{o c}\right)$ as a function of light illumination intensity (a); and $V_{o c}$ decay of the reference and GUTS-4-MAPbI 3 cells (b).

By analysing the open-circuit voltage as a function of light illumination intensity (Fig. 6a), we confirm that besides direct/radiative recombination, trap-assisted recombination exists in both the GUTS-4-MAPbI 3 and the reference solar cells since the ideality factor, $m$, of both cells $\left(m_{1}=1.46\right.$ for the reference cell and $m_{2}=1.25$ for GUTS-4-MAPbI 3 cell) are greater than $1 .{ }^{55,56}$ However, compared to the reference cell, the contribution of trap-assisted recombination is smaller in the GUTS-4-MAPbI 3 cell since $m_{2}<m_{1}$, which is consistent with the value of enhanced shunt resistance and surface charge recombination resistance of the device as shown above.

Photovoltage decay is another effective method to investigate the recombination in perovskite solar cells. Fig. $6 \mathrm{~b}$ illustrates the decay of $V_{o c}$ as a function of time upon removal of light illumination. Basically, a 
longer decay time of $V_{o c}$ is indicative of longer charge carrier life time, as can be found by the following equation: ${ }^{57}$

$$
\tau_{i r}=\left(-\frac{1}{V} \frac{d V}{d t}\right)^{-1}
$$

Where $\tau_{i r}$ is instantaneous relaxation time and $d V / d t$ is the decay rate of $V_{o c}$. The $V_{o c}$ of both types of cells drops to nearly zero within 25 seconds (Fig. 6). However, the GUTS-4-MAPbI 3 cell shows a much slower decay pattern (Fig. 6b, red curve), indicative of a prolonged recombination period or longer carrier relaxation time, in accordance with the larger surface capacitance, $C_{s}$ observed in EIS (Fig. 5b). This result again confirms that the perovskite interface contacts have been improved with GUTS-4 post treatment. We are aware that light soaking prior to $V_{o c}$ decay measurement can give an electrostatic contribution to the photovoltage of PSCs as reported previously. ${ }^{58}$ In our case, an illumination pulse with duration of $\sim 2 \mathrm{~s}$ provided by a white light LED with low intensity equivalent to 0.15 sun was used. Therefore, we can rule out the electrostatic-assisted photovoltage decay effect. As suggested by Gottesman et al., that the interface of perovskite and selective contacts play a key role in the $V_{o c}$ decay pattern, ${ }^{58}$ we correlate this prolonged duration of voltage decay to the improvement of perovskite interfaces besides the decrease of defect in the bulk of the perovskite layer.
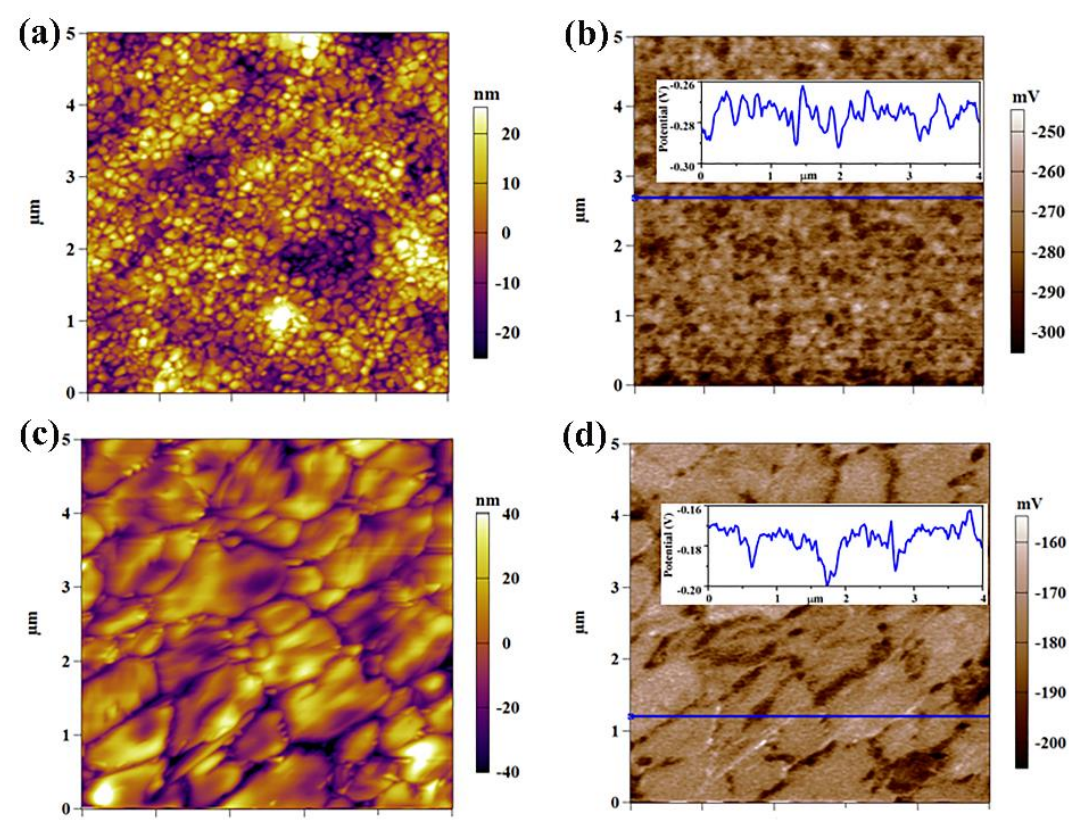

Fig. 7 KPFM topography of (a) Ref-MAPbI ${ }_{3} / \mathrm{SnO}_{2} / \mathrm{FTO}$-glass film and (c) GUTS-4-MAPbI $3 / \mathrm{SnO}_{2} / \mathrm{FTO}-$ glass film; (b) and (d) are the corresponding contact potential difference (CPD) images. 
We carried out Kelvin probe force microscopy (KPFM) measurements to study the electronic properties of $\mathrm{MAPbI}_{3}$ surface. KPFM topography of these films showing in Fig. 7a, c is in excellent agreement with the top-view SEM shown in Fig. 1a, c. The micrographs show that although the grain coarsening slightly increases the surface roughness of the $\mathrm{MAPbI}_{3}$ film from $8.87 \mathrm{~nm}$ to 12.91 $\mathrm{nm}$, it effectively enlarges the grain size of GUTS-4-MAPbI 3 while maintaining film uniformity over a large area $\left(5 \times 5 \mu \mathrm{m}^{2}\right)($ Fig. $7 \mathrm{a}, \mathrm{c})$.

The mean value of contact potential differences (CPD) of the GUTS-4-MAPbI film is $0.1 \mathrm{~V}$ higher than the reference sample, indicating a down-shifted of the electron quasi-Fermi level of the perovskite film (Fig. 7b, d). It has been reported that the conduction band of $\mathrm{SnO}_{2}$ layer is $\sim 170$ $m e V$ below that of the $\mathrm{MAPbI}_{3}$ perovskite film. ${ }^{59}$ Therefore, the increase of the electron quasi-Fermi level of the GUTS-4-MAPbI 3 leads to improved energy band alignment with adjacent with $\mathrm{SnO}_{2}$, which is likely to facilitate the electron extraction along the $\mathrm{MAPbI}_{3} / \mathrm{SnO}_{2}$ interface, and thus higher $V_{o c}$ and $F F$ of the resultant device.

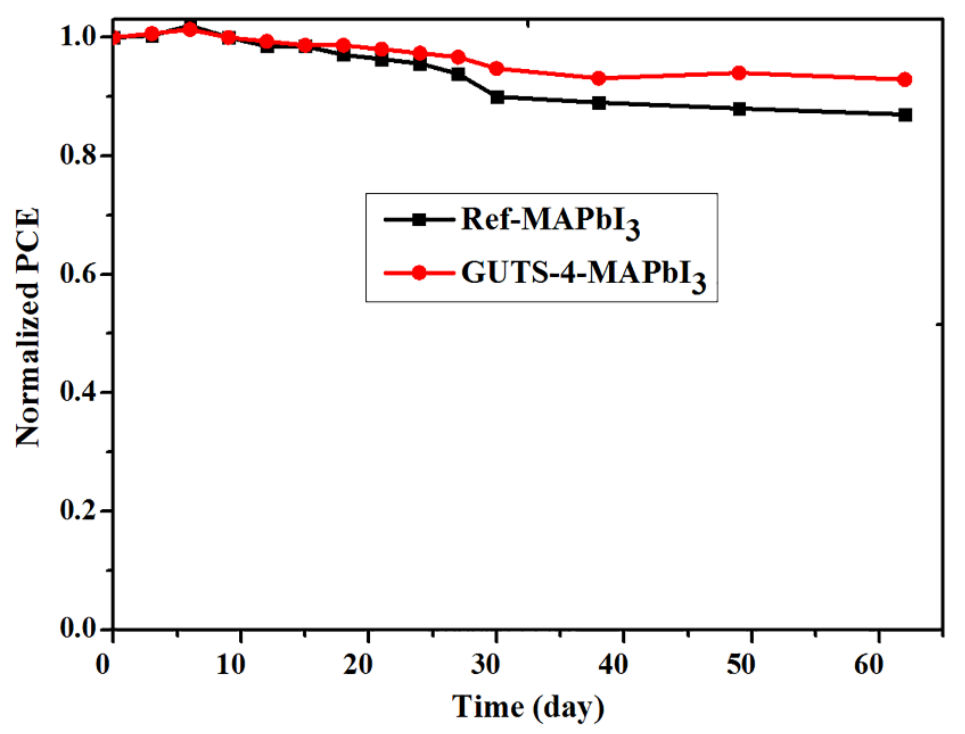

Fig. 8 Moisture stability of the ref-MAPbI 3 cell (black curve) and the GUTS-4-MAPbI 3 cell (red curve). The solar cells were stored in a desiccator with a relative humidity of $\sim 33 \%$ in dark.

The stability of the reference $\mathrm{MAPbI}_{3}$ device and the GUTS-4-MAPbI 3 based device were monitored by measuring their performance every three days (Fig. 8). Both devices show similar stability patterns, where 
the performance increases in the first few days due to the hole-conductivity enhancement of SpiroOMeTAD in air. After this, the performance slowly decreases, which is correlated to the degradation of $\mathrm{MAPbI}_{3}$ layer. ${ }^{4}$ After 60 days storage in dry air $(\mathrm{RH} 33 \%)$, the reference cell retained $87 \%$ of PCE while the GUTS-4-MAPbI 3 cell preserved 93\% of PCE (Fig. 8). The better moisture stability of the GUTS-4$\mathrm{MAPbI}_{3}$ cell, as compared to the reference cell could be associated with the better perovskite film quality with less defects, which reduces the probability of water penetration and degradation of perovskites. ${ }^{46,50}$ 


\section{Conclusions}

We have here demonstrated the effect of GUTS-assisted Ostwald ripening post treatment on the morphology and charge recombination of $\mathrm{MAPbI}_{3}$ film and its interfaces. It was discovered that the concentration of GUTS precursor plays a key role on crystal structure, optical properties, morphology and surface potential of perovskite film. An optimal content of GUTS precursor (GUTS-4, $4 \mathrm{mg} / \mathrm{mL}$ ) induced micron-sized $\mathrm{MAPbI}_{3}$ film, effectively passivates GBs of $\mathrm{MAPbI}_{3}$ film from recombination and positively shifted the film surface potential as confirmed by KPFM. Further investigation of device recombination kinetics showed that the GUTS-4-MAPbI 3 solar cells have higher interfacial charge recombination resistance and lower charge extraction resistance compared to that of the reference $\mathrm{MAPbI}_{3}$ cell, which is in excellent agreement with the results of $V_{o c}$ decay studies. In addition, compared to the pristine $\mathrm{MAPbI}_{3}$, the GUTS-4-MAPbI${ }_{3}$ device had lower ideality factor, suggesting less non-radiative recombination. The resultant performance of planar PSCs was improved by $20 \%$, from average PCE of $12.7 \%$ for the reference $\mathrm{MAPbI}_{3}$ to $15.2 \%$ for GUTS-4-MAPbI 3 cells, mainly due to the enhancement of the $V_{o c}$ and $F F$. In addition, devices with GUTS-4-MAPbI 3 absorber showed less-pronounced hysteresis in the $J-V$ curve and were more inert to moisture than untreated films. This work provides new insight into the mechanism that governs the morphology and optoelectronic properties of $\mathrm{MAPbI}_{3}$ film for high energy conversion efficiency. 


\section{Acknowledgements}

This work was supported by Australian Research Council Future Fellowship (FT120100674) and Queensland-Chinese Academy of Science (Q-CAS) collaborative research fund. N.D.P thanks Queensland University of Technology (QUT) postgraduate scholarship and CSIRO top-up scholarship. The data of XRD, SEM reported in this paper were obtained at the Central Analytical Research facility (CARF), QUT. Access to CARF was supported by the generous funding from Science and Engineering faculty, QUT. In addition, we acknowledge the measurement of KPFM by the Queensland node of the Australian national Fabrication Facility (ANFF), a company established under the National Collaborative Research Infrastructure Strategy. We thank financial support by MINECO of Spain under project (MAT2013-47192-C3-1-R), and Generalitat Valenciana (ACOMP/2015/105). A. G. would like to thank the Spanish Ministerio de Economía y Competitividad for a Ramón y Cajal Fellowship (RYC-2014-16809). 


\section{Reference}

1. M. Gratzel, Nat Mater, 2014, 13, 838-842.

2. A. Kojima, K. Teshima, Y. Shirai and T. Miyasaka, Journal of the American Chemical Society, 2009, 131, 6050-6051.

3. NREL, Best Research Cells Efficiencies, http://www.nrel.gov/ncpv/images/efficiency_chart.jpg).

4. M. M. Lee, J. Teuscher, T. Miyasaka, T. N. Murakami and H. J. Snaith, Science, 2012, 338, 643-647.

5. I. Chung, B. Lee, J. He, R. P. H. Chang and M. G. Kanatzidis, Nature, 2012, 485, 486-489.

6. $\quad$ M. Liu, M. B. Johnston and H. J. Snaith, Nature, 2013, 501, 395-398.

7. M. Saliba, T. Matsui, J.-Y. Seo, K. Domanski, J.-P. Correa-Baena, M. K. Nazeeruddin, S. M. Zakeeruddin, W. Tress, A. Abate, A. Hagfeldt and M. Gratzel, Energy \& Environmental Science, 2016, 9, 1989-1997.

8. N. J. Jeon, J. H. Noh, Y. C. Kim, W. S. Yang, S. Ryu and S. I. Seok, Nat Mater, 2014, 13, 897-903.

9. N. Ahn, D.-Y. Son, I.-H. Jang, S. M. Kang, M. Choi and N.-G. Park, Journal of the American Chemical Society, 2015, 137, 8696-8699.

10. N. D. Pham, V. T. Tiong, P. Chen, L. Wang, G. Wilson, J. M. Bell and H. Wang, Journal of Materials Chemistry A, 2017, DOI: 10.1039/C6TA11139D.

11. C. Bi, Q. Wang, Y. Shao, Y. Yuan, Z. Xiao and J. Huang, Nature Communications, 2015, 6, 7747.

12. Y. Shao, Y. Fang, T. Li, Q. Wang, Q. Dong, Y. Deng, Y. Yuan, H. Wei, M. Wang, A. Gruverman, J. Shield and J. Huang, Energy \& Environmental Science, 2016, 9, 1752-1759.

13. J. S. Yun, J. Seidel, J. Kim, A. M. Soufiani, S. Huang, J. Lau, N. J. Jeon, S. I. Seok, M. A. Green and A. HoBaillie, Advanced Energy Materials, 2016, 6, 1600330-n/a.

14. $\quad$ W.-J. Yin, T. Shi and Y. Yan, Applied Physics Letters, 2014, 104, 063903.

15. H.-S. Duan, H. Zhou, Q. Chen, P. Sun, S. Luo, T.-B. Song, B. Bob and Y. Yang, Physical Chemistry Chemical Physics, 2015, 17, 112-116.

16. P. Xu, S. Chen, H.-J. Xiang, X.-G. Gong and S.-H. Wei, Chemistry of Materials, 2014, 26, 6068-6072.

17. W. E. I. Sha, X. Ren, L. Chen and W. C. H. Choy, Applied Physics Letters, 2015, 106, 221104. 
18. S. van Reenen, M. Kemerink and H. J. Snaith, The Journal of Physical Chemistry Letters, 2015, 6, 38083814.

19. W. Nie, H. Tsai, R. Asadpour, J.-C. Blancon, A. J. Neukirch, G. Gupta, J. J. Crochet, M. Chhowalla, S. Tretiak, M. A. Alam, H.-L. Wang and A. D. Mohite, Science, 2015, 347, 522-525.

20. M. Yang, Y. Zhou, Y. Zeng, C.-S. Jiang, N. P. Padture and K. Zhu, Advanced Materials, 2015, 27, 63636370.

21. Y. C. Kim, N. J. Jeon, J. H. Noh, W. S. Yang, J. Seo, J. S. Yun, A. Ho-Baillie, S. Huang, M. A. Green, J. Seidel, T. K. Ahn and S. I. Seok, Advanced Energy Materials, 2016, 6, 1502104-n/a.

22. C. Roldan-Carmona, P. Gratia, I. Zimmermann, G. Grancini, P. Gao, M. Graetzel and M. K. Nazeeruddin, Energy \& Environmental Science, 2015, 8, 3550-3556.

23. H. Yu, F. Wang, F. Xie, W. Li, J. Chen and N. Zhao, Advanced Functional Materials, 2014, 24, 7102-7108.

24. Y. Tidhar, E. Edri, H. Weissman, D. Zohar, G. Hodes, D. Cahen, B. Rybtchinski and S. Kirmayer, Journal of the American Chemical Society, 2014, 136, 13249-13256.

25. C. Wang, D. Zhao, Y. Yu, N. Shrestha, C. R. Grice, W. Liao, A. J. Cimaroli, J. Chen, R. J. Ellingson, X. Zhao and Y. Yan, Nano Energy, 2017, 35, 223-232.

26. M. K. Kim, T. Jeon, H. I. Park, J. M. Lee, S. A. Nam and S. O. Kim, CrystEngComm, 2016, 18, 6090-6095.

27. Y. Yu, C. Wang, C. R. Grice, N. Shrestha, J. Chen, D. Zhao, W. Liao, A. J. Cimaroli, P. J. Roland, R. J. Ellingson and Y. Yan, ChemSusChem, 2016, 9, 3288-3297.

28. W. Ke, C. Xiao, C. Wang, B. Saparov, H.-S. Duan, D. Zhao, Z. Xiao, P. Schulz, S. P. Harvey, W. Liao, W. Meng, Y. Yu, A. J. Cimaroli, C.-S. Jiang, K. Zhu, M. Al-Jassim, G. Fang, D. B. Mitzi and Y. Yan, Advanced Materials, 2016, 28, 5214-5221.

29. Y.-H. Chiang, M.-H. Li, H.-M. Cheng, P.-S. Shen and P. Chen, ACS Applied Materials \& Interfaces, 2017, 9, 2403-2409.

30. W. Zhu, C. Bao, Y. Wang, F. Li, X. Zhou, J. Yang, B. Lv, X. Wang, T. Yu and Z. Zou, Dalton Transactions, $2016,45,7856-7865$.

31. Z. Xiao, Q. Dong, C. Bi, Y. Shao, Y. Yuan and J. Huang, Advanced Materials, 2014, 26, 6503-6509.

32. M. Yang, T. Zhang, P. Schulz, Z. Li, G. Li, D. H. Kim, N. Guo, J. J. Berry, K. Zhu and Y. Zhao, Nature Communications, 2016, 7, 12305. 
33. Z. Zhou, Z. Wang, Y. Zhou, S. Pang, D. Wang, H. Xu, Z. Liu, N. P. Padture and G. Cui, Angewandte Chemie International Edition, 2015, 54, 9705-9709.

34. Y. Jiang, E. J. Juarez-Perez, Q. Ge, S. Wang, M. R. Leyden, L. K. Ono, S. R. Raga, J. Hu and Y. Qi, Materials Horizons, 2016, 3, 548-555.

35. Y. Shao, Z. Xiao, C. Bi, Y. Yuan and J. Huang, Nature Communications, 2014, 5, 5784.

36. J. Xu, A. Buin, A. H. Ip, W. Li, O. Voznyy, R. Comin, M. Yuan, S. Jeon, Z. Ning, J. J. McDowell, P. Kanjanaboos, J.-P. Sun, X. Lan, L. N. Quan, D. H. Kim, I. G. Hill, P. Maksymovych and E. H. Sargent, $2015,6,7081$.

37. P.-W. Liang, C.-C. Chueh, S. T. Williams and A. K. Y. Jen, Advanced Energy Materials, 2015, 5, 1402321n/a.

38. D. Bi, W. Tress, M. I. Dar, P. Gao, J. Luo, C. Renevier, K. Schenk, A. Abate, F. Giordano, J.-P. Correa Baena, J.-D. Decoppet, S. M. Zakeeruddin, M. K. Nazeeruddin, M. Grätzel and A. Hagfeldt, Science Advances, 2016, 2.

39. H. Xu, Y. Wu, J. Cui, C. Ni, F. Xu, J. Cai, F. Hong, Z. Fang, W. Wang, J. Zhu, L. Wang, R. Xu and F. Xu, Physical Chemistry Chemical Physics, 2016, 18, 18607-18613.

40. N. D. Marco, H. Zhou, Q. Chen, P. Sun, Z. Liu, L. Meng, E.-P. Yao, Y. Liu, A. Schiffer and Y. Yang, Nano Letters, 2016, 16, 1009-1016.

41. H. A. Harms, N. Tetreault, N. Pellet, M. Bensimon and M. Gratzel, Faraday Discussions, 2014, 176, 251269.

42. S. Yang, Y. Chen, Y. C. Zheng, X. Chen, Y. Hou and H. G. Yang, RSC Advances, 2015, 5, 69502-69508.

43. G. Madras and B. J. McCoy, The Journal of Chemical Physics, 2002, 117, 6607-6613.

44. J. A. Marqusee and J. Ross, The Journal of Chemical Physics, 1983, 79, 373-378.

45. Q. Jiang, D. Rebollar, J. Gong, E. L. Piacentino, C. Zheng and T. Xu, Angewandte Chemie International Edition, 2015, 54, 7617-7620.

46. Z. Liu, J. Hu, H. Jiao, L. Li, G. Zheng, Y. Chen, Y. Huang, Q. Zhang, C. Shen, Q. Chen and H. Zhou, Advanced Materials, 2017, DOI: 10.1002/adma.201606774, 1606774-n/a.

47. N. K. Noel, S. N. Habisreutinger, B. Wenger, M. T. Klug, M. T. Horantner, M. B. Johnston, R. J. Nicholas, D. T. Moore and H. J. Snaith, Energy \& Environmental Science, 2017, 10, 145-152. 
48. A. Guerrero, J. You, C. Aranda, Y. S. Kang, G. Garcia-Belmonte, H. Zhou, J. Bisquert and Y. Yang, ACS Nano, 2016, 10, 218-224.

49. Y. Zhao and K. Zhu, Chemical Communications, 2014, 50, 1605-1607.

50. C.-H. Chiang, M. K. Nazeeruddin, M. Gratzel and C.-G. Wu, Energy \& Environmental Science, 2017, 10, 808-817.

51. Q. Lin, A. Armin, R. C. R. Nagiri, P. L. Burn and P. Meredith, Nat Photon, 2015, 9, 106-112.

52. I. Zarazua, G. Han, P. P. Boix, S. Mhaisalkar, F. Fabregat-Santiago, I. Mora-Seró, J. Bisquert and G. GarciaBelmonte, The Journal of Physical Chemistry Letters, 2016, 7, 5105-5113.

53. A. Guerrero, G. Garcia-Belmonte, I. Mora-Sero, J. Bisquert, Y. S. Kang, T. J. Jacobsson, J.-P. Correa-Baena and A. Hagfeldt, The Journal of Physical Chemistry C, 2016, 120, 8023-8032.

54. I. Zarazua, J. Bisquert and G. Garcia-Belmonte, The Journal of Physical Chemistry Letters, 2016, 7, 525528.

55. W. Tress, K. Leo and M. Riede, Applied Physics Letters, 2013, 102, 163901.

56. V. V. Brus, F. Lang, J. Bundesmann, S. Seidel, A. Denker, B. Rech, G. Landi, H. C. Neitzert, J. Rappich and N. H. Nickel, Advanced Electronic Materials, 2017, 3, 1600438-n/a.

57. A. Zaban, M. Greenshtein and J. Bisquert, ChemPhysChem, 2003, 4, 859-864.

58. R. Gottesman, P. Lopez-Varo, L. Gouda, Juan A. Jimenez-Tejada, J. Hu, S. Tirosh, A. Zaban and J. Bisquert, Chem, 2016, 1, 776-789.

59. J. P. Correa Baena, L. Steier, W. Tress, M. Saliba, S. Neutzner, T. Matsui, F. Giordano, T. J. Jacobsson, A. R. Srimath Kandada, S. M. Zakeeruddin, A. Petrozza, A. Abate, M. K. Nazeeruddin, M. Gratzel and A. Hagfeldt, Energy \& Environmental Science, 2015, 8, 2928-2934. 